\title{
Technological Typomorphic Associations in Caustobiolites and Methods of Their Extraction
}

\author{
Artyom Romashev ${ }^{1, *} \mathbb{D}$, Dongsheng $\mathrm{He}^{2}$, Tatiana Aleksandrova ${ }^{1}$ and Nadezhda Nikolaeva ${ }^{1}$ \\ 1 Mineral Processing Department, Saint-Petersburg Mining University, 199106 Saint-Petersburg, Russia; \\ Aleksandrova_TN@pers.spmi.ru (T.A.); Nikolaeva_NV@pers.spmi.ru (N.N.) \\ 2 School of Resources \& Safety Engineering, Wuhan Institute of Technology, Wuhan 430074, China; \\ hds@wit.edu.cn \\ * Correspondence: romashev_ao@pers.spmi.ru; Tel.: +7-9500048119
}

check for updates

Citation: Romashev, A.; He, D.; Aleksandrova, T.; Nikolaeva, N. Technological Typomorphic Associations in Caustobiolites and Methods of Their Extraction. Metals 2021, 11, 121. https://doi.org/ $10.3390 /$ met11010121

Received: 25 November 2020 Accepted: 3 January 2021 Published: 9 January 2021

Publisher's Note: MDPI stays neutral with regard to jurisdictional clai$\mathrm{ms}$ in published maps and institutional affiliations.

Copyright: (C) 2021 by the authors. Licensee MDPI, Basel, Switzerland. This article is an open access article distributed under the terms and conditions of the Creative Commons Attribution (CC BY) license (https:// creativecommons.org/licenses/by/ $4.0 /)$.

\begin{abstract}
Heavy oil is considered as a multipurpose complex mineral, and the processing of heavy oils as a "complex problem", aimed both at increasing the yield of light fractions and "transport" ability of oil, and at extracting metals from heavy asphaltene resinous fraction. The recovery of heavy metals (such as vanadium, nickel, titanium, iron, etc.) from heavy oil was performed by cavitation extraction technology with the use of light hydrocarbon solvents and chemical extractants, including a stage of extraction in an ultrasonic field with separation of insoluble fraction of asphaltenes in which a significant part of initial heavy metals and sulfur is concentrated, followed by re-extraction of metals and magnetic separation of metal aggregates.
\end{abstract}

Keywords: heavy oil; extraction; heavy metals; cavitation; rheology

\section{Introduction}

The problem of the depletion of traditional deposits of liquid and solid extractable resources has resulted in the necessity for search and implementation of new technologies for their complex processing. The adoption of such technologies will count for a great deal for both the environment and the economy in terms of the principles of sustainable development [1-5]. At present, light oil deposits are decreasing and, consequently, many oil companies have started to extract and process heavy oil and even natural bitumen. Apart from coal and hydrogen, this oil contains a wide range of different chemical elements, including various metals (vanadium $(\mathrm{V})$, nickel $(\mathrm{Ni})$, titanium $(\mathrm{Ti})$, gold $(\mathrm{Au})$, chromium $(\mathrm{Cr})$, manganese $(\mathrm{Mn})$, iron $(\mathrm{Fe})$, etc.) [6-11]. For example, each ton of heavy oil of Athabasca oil sands (Canada) contains $250 \mathrm{~g}$ of vanadium, $100 \mathrm{~g}$ of nickel [8]. Heavy oil of many Russian deposits contains a lot of vanadium, nickel, and silver. The oil of Samotlor deposit contains, in addition to vanadium and nickel, gold, chromium, manganese, iron, and other metals. If we consider traditional deposits of metals, it is economically reasonable to consider the development of ore deposits containing not less than $0.1 \%$ of metal. Moreover, the grade of some metals in various types of oils and bitumen is close to this value, but unlike rocks, they do not require the development of deposits, blasting operations, removal of ore from open-pit mines, crushing and treatment. Previous studies show that some metals accumulate in large amounts in a number of cases compared to their clusters in the lithosphere. This allows us to estimate the economic and technological feasibility of these metals extraction from oil, while improving the quality of basic petroleum products [12-20].

Since the majority of metals are concentrated in asphaltene and resins, it is natural that the processes of deasphalting in the processes of preparation for processing heavy oils and oil residues happens at the same time, to a greater or lesser extent, as the processes of demetalization of this raw material. The processes of destructive processing of heavy oils and residues are shown in Figure 1 [7-9]. 


\begin{tabular}{|c|c|c|c|c|c|c|}
\hline $\begin{array}{l}\text { The essence } \\
\text { of removal }\end{array}$ & \begin{tabular}{|c|} 
Extraction \\
Removal of \\
metals in \\
resinous and \\
asphaltenic \\
substances \\
separated \\
from oil by \\
coagulants.
\end{tabular} & $\begin{array}{l}\text { Adsorption } \\
\text { Extraction of } \\
\text { metals from } \\
\text { crude oil using } \\
\text { adsorbents, } \\
\text { supplemented } \\
\text { by heat } \\
\text { treatment }\end{array}$ & $\begin{array}{c}\text { Catalytic } \\
\text { Destruction of } \\
\text { metal- } \\
\text { containing } \\
\text { compounds in } \\
\text { the presence of } \\
\text { a fissile catalyst } \\
\text { and metal } \\
\text { deposition on it }\end{array}$ & $\begin{array}{c}\text { Hydrogenation } \\
\text { Destruction of } \\
\text { metal- } \\
\text { containing } \\
\text { compounds by } \\
\text { hydrogenation } \\
\text { processing and } \\
\text { metal } \\
\text { deposition on } \\
\text { the catalyst }\end{array}$ & $\begin{array}{l}\text { Thermal } \\
\text { Thermal } \\
\text { destruction of } \\
\text { metal-containing } \\
\text { compounds and } \\
\text { concentration of } \\
\text { metals in } \\
\text { thermolysis } \\
\text { residues, in coke }\end{array}$ & $\begin{array}{l}\text { Combined } \\
\text { Destruction of } \\
\text { metal-containing } \\
\text { compounds by } \\
\text { hydrogenation } \\
\text { processing } \\
\text { without a } \\
\text { catalytic } \\
\text { converter }\end{array}$ \\
\hline $\begin{array}{l}\text { Process } \\
\text { title }\end{array}$ & $\begin{array}{c}\text { Solvent } \\
\text { deasphalting }\end{array}$ & $\begin{array}{l}\text { Adsorption } \\
\text { cleaning. } \\
\text { Selective } \\
\text { cleaning. } \\
\text { Adsorption- } \\
\text { catalytic } \\
\text { cleaning }\end{array}$ & $\begin{array}{l}\text { Catalytic } \\
\text { cracking }\end{array}$ & $\begin{array}{l}\text { Hydrotreating. } \\
\text { Hydrocracking }\end{array}$ & $\begin{array}{l}\text { Visbreaking, } \\
\text { Thermal Cracking, } \\
\text { Delayed coking, } \\
\text { Fluid Cracking, } \\
\text { Flexicoking }\end{array}$ & $\begin{array}{l}\text { Hydrovisbreaking, } \\
\text { Hydrocoking, } \\
\text { Hydropirolysis, } \\
\text { Donor Solvent } \\
\text { Cracking }\end{array}$ \\
\hline $\begin{array}{c}\text { Degree of } \\
\text { metal } \\
\text { removal, } \%\end{array}$ & $70-80$ & $80-95$ & $80-96$ & $60-90$ & $70-80$ & $60-80$ \\
\hline
\end{tabular}

Figure 1. Classification of the main processes of destructive processing of heavy oils and residues.

Among the possible directions of improvement of methods of deep processing of heavy oils, 4 main directions can be singled out: the method of slow coking and production of oil coke, thermal decomposition of organometallic compounds of resinous and asphaltene substances with the subsequent absorption of released metal atoms in the pores of corresponding adsorbents, processes of residue deasphaltization with the use of sub and supercritical fluids as extractants and processes of catalytic hydrodeasphaltization and hydrodemetalization.

As a result of the analysis of previous studies in the field of deep processing of heavy oil, heavy oil residues, and natural bitumen, the leading directions of theoretical and experimental research on the processing of high-viscosity oils and natural bitumen for the extraction of valuable metals were identified and justified. It was found that the problems of metal extraction from oil can be partially solved by using directional physical and chemical effects, such as electrostatic field, magnetic field and ultrasonic treatment which allow us to control the structural and mechanical properties and intensify the concentration of metals in certain classes of compounds [6-10,19].

Heavy oil can be considered as a multipurpose complex mineral, and the processing of heavy oils as a "complex problem", aimed both at increasing the yield of light fractions and "transport" ability of oil, and at extracting metals from heavy asphaltene resinous fraction.

In this work, an attempt was made to justify and develop a technology for the extraction of heavy metals at the micro and macro levels from heavy oils of the Yaregskoye field using directed physical and chemical effects based on experimental studies and numerical modeling. At the same time, the development of physical-chemical and technological bases of extraction of heavy metals from oil and bitumen feedstock based on the intensification of extraction processes by the impact of different genesis, the use of selective reagents of directional action at the main stages of concentration and separation of fractions and separation of valuable components has scientific novelty and allows us to create new technological solutions based on fundamental approaches of rheology and petrochemistry and to adapt them to specific types of feedstock.

\section{Materials and Methods}

The Yaregskiy oil was selected to study the possibility of extracting heavy metals from heavy oil. This oil belongs to the class of heavy $\left(0.945 \mathrm{~g} / \mathrm{cm}^{3}\right)$, high-viscosity 
$\left(10,000-12,000 \mathrm{mPa} \cdot \mathrm{s}\right.$ at an initial temperature of $\left.8{ }^{\circ} \mathrm{C}\right)$, low-sulfur and low-paraffin, and it contains a significant amount of heavy metals, e.g., vanadium, nickel, iron, titanium, noble and rare-earth metals [12-23]. The analysis of the initial sample and separation products was performed by atomic absorption, X-ray fluorescence, mass spectrometry with inductively coupled plasma, and instrumental neutron activation analysis (INAA) (St. Petersburg Konstantinov Institute of Nuclear Physics. B. P. Konstantinov Institute of Nuclear Physics, St. Petersburg, Russia). Optical methods and electron microscopy (Hitachi High-Technologies Corporation, Tokyo, Japan) with X-ray microanalysis were used for mineralogical and petrographic studies. Chemical analysis was performed by spectral method with inductively coupled plasma on the spectrometer iCAP 6300 DUO (Thermo Scientific, Waltham, MA, USA) (Figure 2 and Table 1).

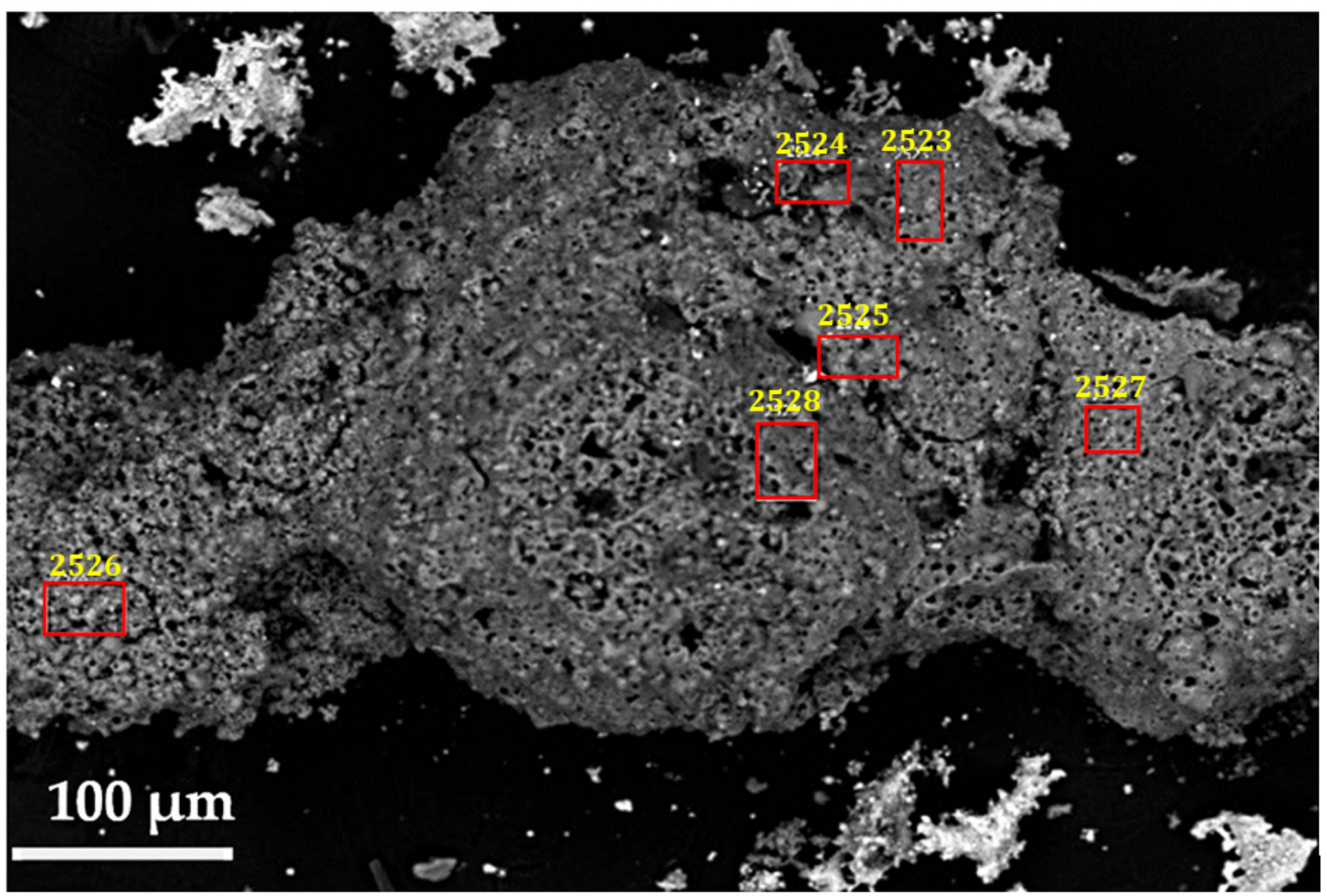

Figure 2. The micrograph of mineral part of heavy oil.

Table 1. The results of atomic emission analysis.

\begin{tabular}{ccccccccccc}
\hline \multicolumn{10}{c}{ Grade (g/t) } \\
\hline $\mathbf{M g}$ & $\mathbf{A l}$ & $\mathbf{S i}$ & $\mathbf{K}$ & $\mathbf{C a}$ & $\mathbf{T i}$ & $\mathbf{V}$ & $\mathbf{C r}$ & $\mathbf{M n}$ & $\mathbf{F e}$ & $\mathbf{N i}$ \\
\hline 15.2 & 3.26 & 21.5 & 0.73 & 1.76 & 51 & 18.1 & 0.034 & 0.16 & 117.17 & 3.4 \\
\hline $\mathbf{C u}$ & $\mathbf{Z n}$ & $\mathbf{A s}$ & $\mathbf{S e}$ & $\mathbf{S r}$ & $\mathbf{Z r}$ & $\mathbf{M o}$ & $\mathbf{P b}$ & $\mathbf{C d}$ & $\mathbf{S n}$ & $\mathbf{S b}$ \\
\hline 0.047 & 4.24 & 0.007 & 0.007 & 0.012 & 0.009 & 0.009 & 0.027 & 0.007 & 0.009 & 0.006 \\
\hline
\end{tabular}

Use of thermal analysis (TA) and thermogravimetric analysis (TG) (TA Instruments, New Castle, USA) in combination with mass spectroscopic analysis (MS) (Shimadzu Corporation, Kyoto, Japan) for the study of heavy oil in the Timan-Pechersk oil and gas province enabled studying in more detail and obtaining updated information on the 
composition and structure of decomposition products of oil residues (Figure 3). Co-heating of Bypass-capillary nozzles and Skimmer allowed us to avoid measurement errors.

(a)

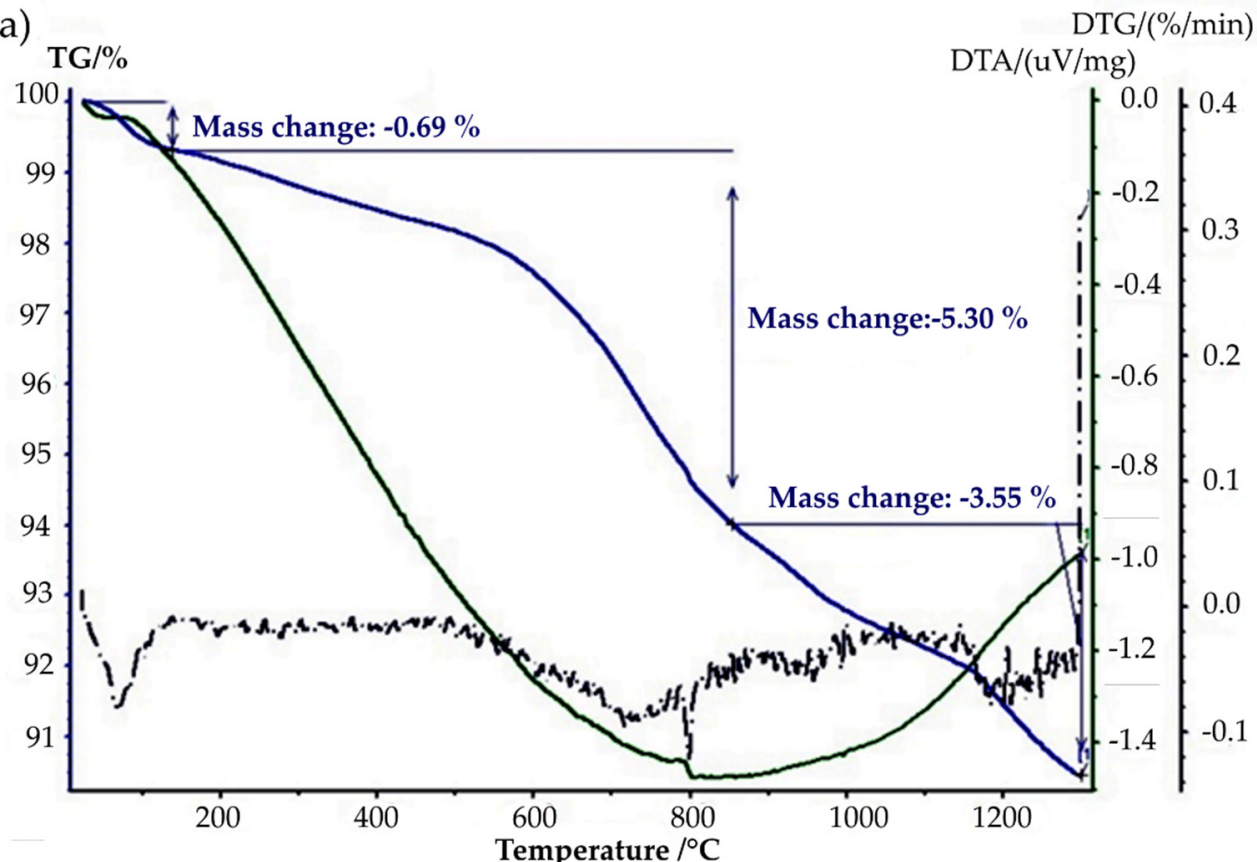

(b)

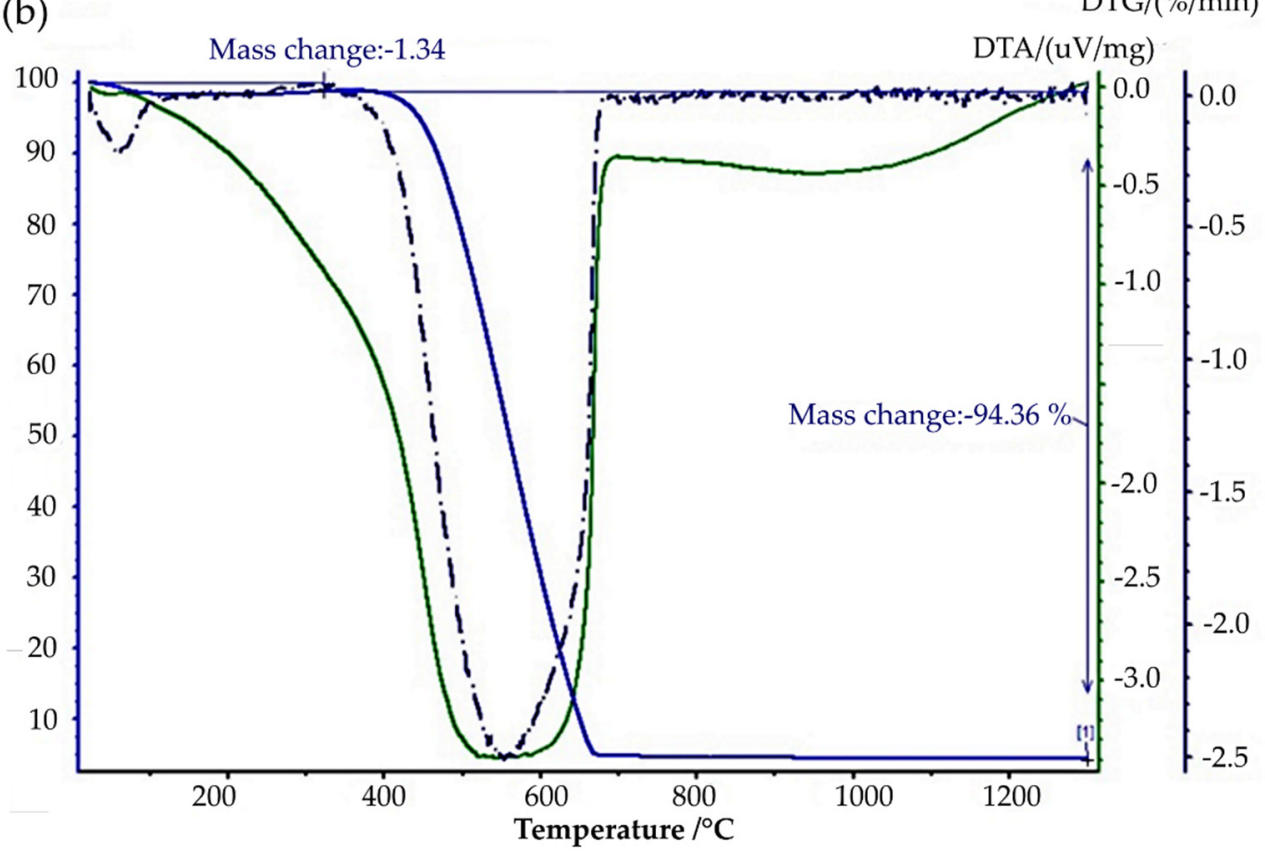

Figure 3. The thermogravimetric analysis of mineral part of the Yaregsky oil in argon (a) and in air (b). Thermogravimetric analysis (TG)-mass change; Differential thermogravimetric analysis (DTG)-decomposition rate; Differential thermal analysis (DTA)-mass change of the heat flux rate (shows the nature of the reaction exo or endothermic).

The measurements were performed in the temperature range from 25 to $1300{ }^{\circ} \mathrm{C}$ in steps of $5 \mathrm{~K} / \mathrm{min}$ in the atmosphere of air and argon. Both kerogen and bitumen are steadily recorded in the residual of heavy oil of the Yaregskiy deposit. Correlation with quantitative chemical analysis and electron microscopy data allows us to state that the elements of kerogen and bituminous organic residues are cadmium, strontium, and a part of vanadium and titanium. 
All technological research was carried out on samples of oil from the Yaregskoye field $(\mathrm{V}=100 \mathrm{~mL})$.

Ultrasonic treatment at the stage of ultrasonic and cavitation processing was carried out on the INLAB I100-6/1-1 ultrasonic unit. Based on the literature analysis [24], the values of ultrasonic pressure intensity for organic media are given in Table 2.

Table 2. Values for optimum degree of impact for liquids used in practice.

\begin{tabular}{ccccc}
\hline Liquid Name & Initial Viscosity, Pa.s & Nonlinearity Index, N & $\begin{array}{c}\text { Optimum Intensity, } \\
\text { W/cm } \mathbf{~}^{2}\end{array}$ & $\begin{array}{c}\text { Optimum Range, } \\
\boldsymbol{\mu m}\end{array}$ \\
\hline Water & 0.00082 & 0 & 1.73 & 0.7 \\
Olive oil & 0.085 & 0 & 4.51 & 1.7 \\
Motor oil & 0.4 & 0 & 19.25 & 7.4 \\
Glycyl alcohol & 0.6 & 0 & 34.4 & 13.3 \\
Ethoxyline resin & 3 & -0.15 & $19.95-24.77$ & $7.7-9.6$ \\
Coal-water slurry (mass & 0.1 & 0.1 & $13.74-18.74$ & $5.3-7.2$ \\
concentration 20\%) & & & \\
\hline
\end{tabular}

The optimal degree of impact for most fluids used in practice does not exceed $40 \mathrm{~W} / \mathrm{cm}^{2}$ at $22 \mathrm{kHz}$, except for dilatant fluids, for which the degree of impact can reach $100 \mathrm{~W} / \mathrm{cm}^{2}$. The reduction or increase in intensity required to form the cavitation area can reach $20 \mathrm{~W} / \mathrm{cm}^{2}$. Preliminary experiments have shown that the numerical indices of the intensity at which "developed" cavitation process occurs in a liquid medium depend mainly on liquid viscosity, for example, for water and alcohol, this value is not more than $5 \mathrm{~W} / \mathrm{cm}^{2}$, for liquids in the viscosity range of $80-100 \mathrm{sPz}-6-8 \mathrm{~W} / \mathrm{cm}^{2}$, and for high-viscosity liquids (more than $400 \mathrm{sPz}$ )-more than $25 \mathrm{~W} / \mathrm{cm}^{2}$.

The operating frequency of the INLAB I100-6/1-1 ultrasonic unit (LLC "Ultrasonic Technology - INLAB", Saint-Petersburf, Russia), which was used in the work, varies from 22 to $44 \mathrm{kHz}$, which allows to reach the intensity of impact from 5 to $25 \mathrm{~W} / \mathrm{cm}^{2}$. Cavitation treatment was carried out in a chamber $(\mathrm{V}=0.5 \mathrm{~L})$ with a stirrer. Stirrer speed varied from 1000 to $5000 \mathrm{rpm}$.

\section{Results}

The recovery of precious metals (such as $\mathrm{V}, \mathrm{Ni}, \mathrm{Ti}, \mathrm{Fe}$, etc.) from heavy oil was performed by cavitation extraction technology with the use of light hydrocarbon solvents and chemical extractants, including the stage of extraction in the ultrasonic field with separation of insoluble fraction of asphaltenes in which a significant part of initial heavy metals and sulfur is concentrated, followed by re-extraction of metals and magnetic separation of metal aggregates (Figure 4).

The main feature of this method is the consistent use of acoustic and cavitation effects, which enables improving the efficiency of mass transfer at the stage of solvent deasphalting (SDA), thereby reducing the required extraction time, due to the catalytic action of hydrogen peroxide, including those formed by physical exposure to the oil suspension.

Sedimentometric and rheological studies, as well as polarization microscopy have suggested the effect of ultrasound on the extraction process and the behavior of the system "(extractant + water) - heavy oil". By treatment of hydrocarbon suspensions by ultrasound, local areas with high values of temperature and pressure are formed in which highly reactive particles are formed; recombination of hydroxyl radicals occurs, with the formation of hydrogen peroxide $\mathrm{H}_{2} \mathrm{O}_{2}$, which is a catalyst for destructive processes.

Scheme:

$$
\begin{aligned}
& \mathrm{H}_{2} \mathrm{O} \stackrel{\mathrm{t}, \mathrm{P}}{\longrightarrow} \bullet \mathrm{OH}+\bullet \\
& \mathrm{H}^{\bullet}+\mathrm{O}_{2} \rightarrow \mathrm{HO}_{2}^{\bullet} \\
& \mathrm{HO}_{2}^{\bullet}+\mathrm{HO}_{2}^{\bullet} \rightarrow \mathrm{H}_{2} \mathrm{O}_{2}+\mathrm{O}_{2} \\
& \bullet \mathrm{OH}+{ }^{\bullet} \mathrm{OH} \rightarrow \mathrm{H}_{2} \mathrm{O}_{2}
\end{aligned}
$$




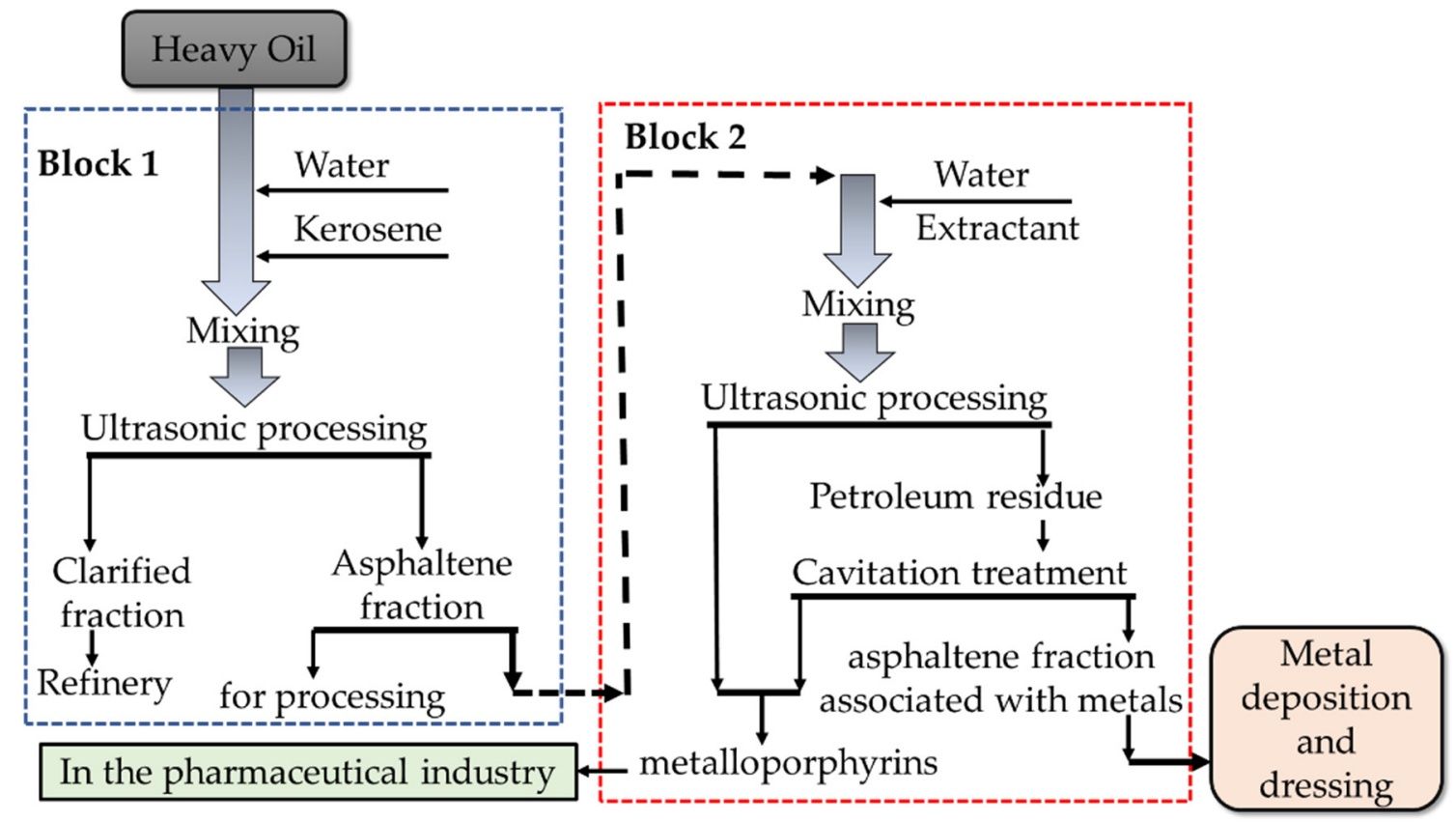

Figure 4. The cavitation extraction system for extracting heavy metals from heavy oil of the Yaregsky deposit.

As a result, the structural viscosity of the system is sharply reduced, and the dynamic shear stress limit disappears.

At the first stage of processing (preparation for recovery), the oil was mixed with water and kerosene in the proportion of 70:15:15. A series of extractants (ethanol, kerosene, morpholine, and tributyl phosphate) were substantiated by previous studies and based on the analysis of a mixotropic series of solvents and extracting ability regarding sulfur [16].

The conducted studies (Figure 5) showed that four extractants have the highest degree of hetero compounds extraction from heavy oils: ethanol, kerosene, methanol, and tributyl phosphate. Therefore, they can be recommended for use both individually and for modeling the composition of the extractant to ensure maximum recovery of hetero compounds from heavy hydrocarbons.

However, it should be noted that at a ratio of aromatic and aliphatic hydrocarbons 2:1 extraction does not occur, due to the complete solubility of the extractant (methanol, acetic acid) in aromatic hydrocarbons. At the same time, kerosene and tributyl phosphate allow to reach the degree of recovery of hetero compounds associated with metals up to $37.98 \%$ and $40.72 \%$, respectively.

At rest, the oil-bitumen suspension (OBS) forms a certain spatial structure consisting of particles of paraffin and asphaltene suspended in light hydrocarbons [16]. Thus, these particles can be considered as a type of degraded framework. The inner frame becomes denser with increasing mass concentration, and considerable effort is required to destroy it.

Analysis of hydraulic losses during the movement of the OBS shows that to start the movement it is necessary to overcome a defined limit of reciprocal viscosity (material yield strength) $\tau_{0}$. This indicates the presence of a plastic constituent (the body of SaintVenant). The deformation acts to overcome the friction force, and the higher concentration is the higher value of material yield strength. Thus, it can be assumed that the material yield strength depends on two components: external friction (for example, on the walls of pipeline) and internal friction (friction associated with the strength of the frame and its elasticity). Therefore, if deformation is applied to the suspension $\left(\tau<\tau_{0}\right)$, then it will not move, and an elastic stress state will arise in the frame.

The friction stress increases in the first stage, but it is still not enough to begin to destroy the frame. Gradually, the framework and internal bonds between particles weaken and the strength of the framework decreases. Thus, two processes occur simultaneously in 
the frame at the first stage: an increase in the friction force and a decrease in the strength of the frame.

The structured flow begins to disperse under the action of friction in the second stage, and when it reaches a certain critical speed, the frame collapses completely, and the flow becomes completely dispersed. Stresses disappear inside the flow at this moment, and its behavior becomes similar to a non-Newtonian fluid. Thus, the suspension exhibits thixotropic properties with increasing speed and turns into a liquid-solid medium, which has a non-Newtonian flow character. The analysis of the transformation of suspension in the process of its movement shows that it has viscous, elastic, and plastic properties.

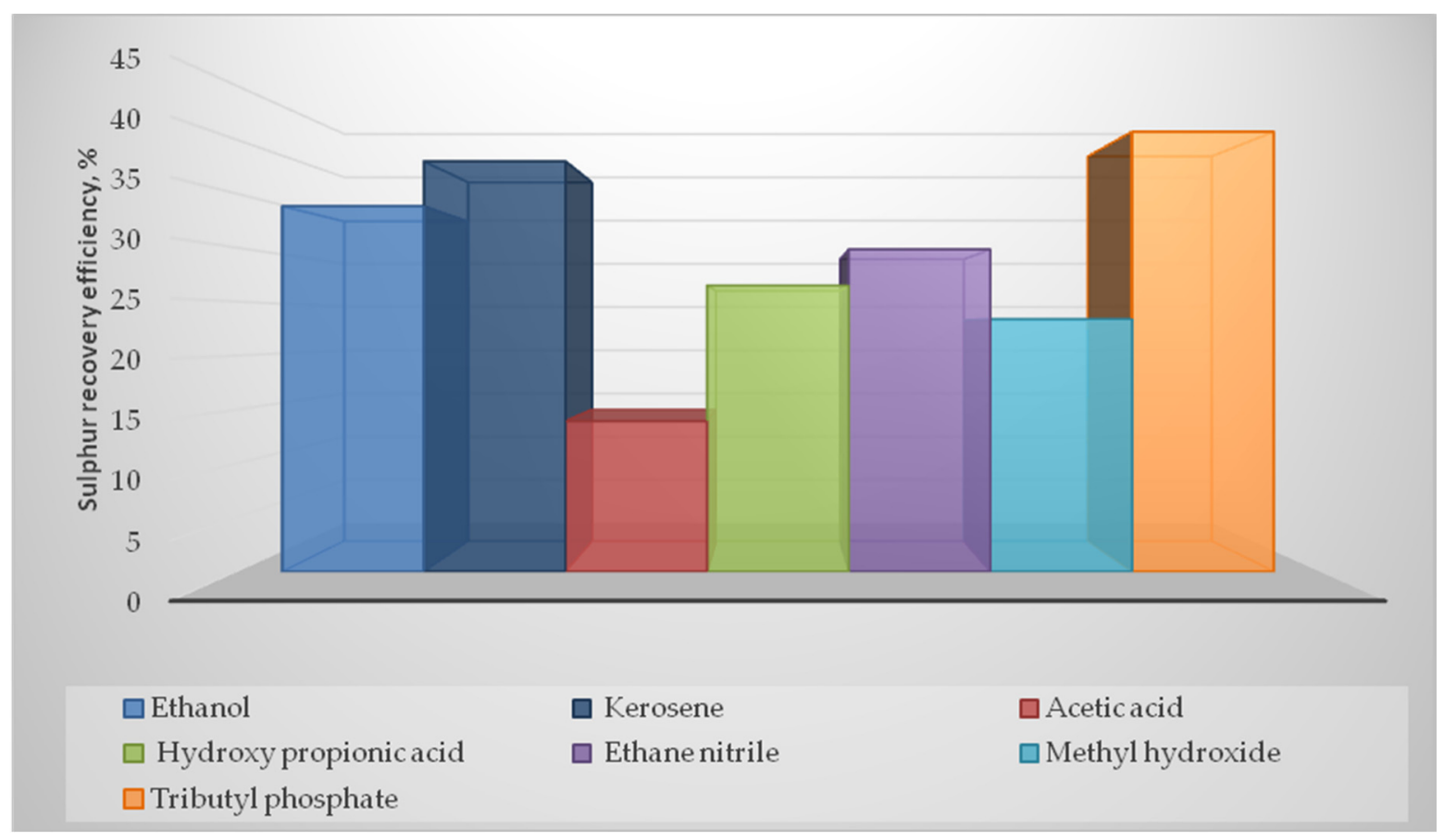

Figure 5. Dependence of the degree of recovery of hetero compounds from heavy oils on the type of extractant.

It is established that the integral relations of the hereditary Boltzmann theory of viscoelasticity are equivalent to linear differential relations with constant coefficients, in the case when the kernel is the sum of exponential functions. However, in practice, functions in the form of exponentials or sums of exponentials are of little use due to the impossibility of describing the process in the initial period of time. This is due to the fact that functions of this kind have a specific meaning (at $t=0$ ). If we assume that the zero time $\mathrm{T}(t)=\infty$, then more complex dependencies based on weakly singular functions should be used. To describe the relaxation processes in heavy oils, it was proposed to use the approximation using the three-parameter weakly singular Koltunov kernel, defined by the formula:

$$
\mathrm{T}(t)=A e^{-\beta t} t^{\alpha-1}
$$

where $A, \alpha, \beta$-rheological parameters depending on the characteristics of the investigated object.

Consider the example of the initialization of the relaxation curve for the object under study. The ultrasound was applied on an INLAB I100-6/1-1 ultrasonic unit for various periods of time, followed by fixing the viscosity coefficient on an SV 10 viscometer manufactured (A\&D Company, Limited, Tokyo, Japan). The results of the study are presented in Figure 6 . 


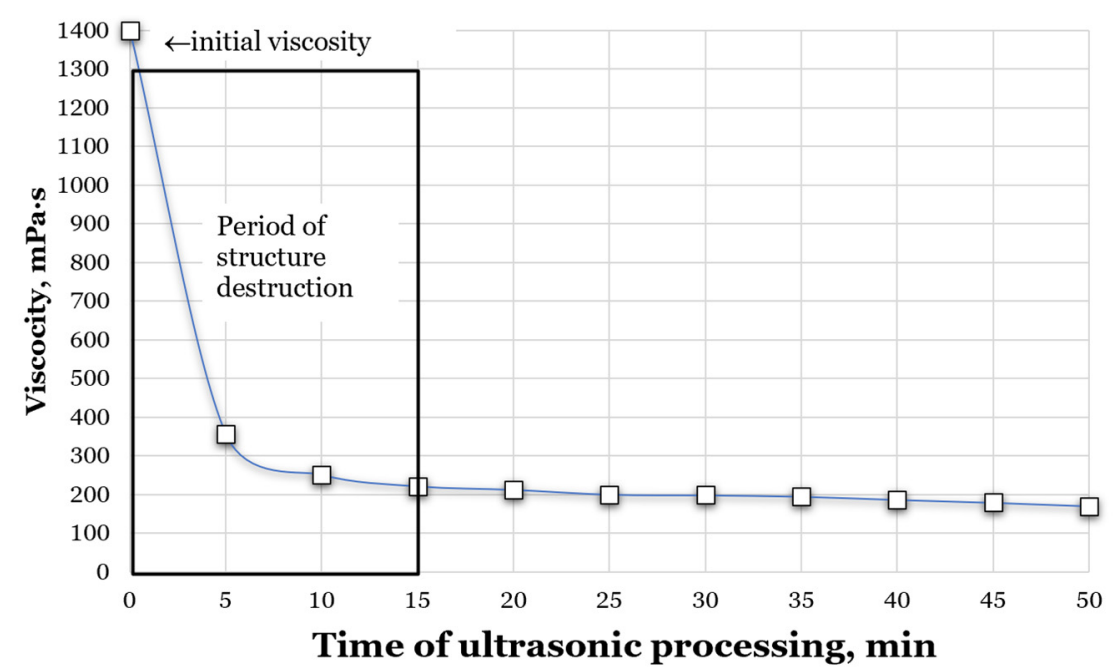

Figure 6. Dependence of the viscosity of oil-bitumen suspension (OBS) on the time of ultrasonic processing.

As can be seen from the graph data, the maximum possible destruction of these parameters occurs after $15 \mathrm{~min}$ of processing. Further processing does not practically change the viscosity value, which is explained by the maximum destruction of the structure at these parameters.

These studies made it possible to justify the time of ultrasonic processing of the mixture ( $15 \mathrm{~min}$ with a frequency of $22 \mathrm{KHz}$ ). At this stage, ultrasound processing enables increasing the yield of volatiles during its distillation. The concentrated asphaltene fraction is mixed with water and chemical extractants in the proportion of 50:25:25\%, respectively (the second stage of processing). The increased amount of water and extractant is caused by the fact that the heavy fraction is extracted after primary processing. As a chemical extractant, tributyl phosphate was chosen. Calculation of electronic and structural characteristics of metal-containing organic complexes and reagents is performed by semi-empirical quantum chemical method using Merck Molecular Force Field 94 (MMFF94) algorithm. This method refers to comparing the given substance with the properties of substances in the program database and on the basis of this analysis, their properties are forecast. The molecular geometries of "substrate-reagent" systems formed in the extraction process were simulated using the conjugate gradient method of Polak-Ribiere in supermolecular approximation without any symmetry limitations and reaching the optimization limit of $0.005 \mathrm{kcal} / \mathrm{mol}$. Calculations of basic spin states were performed by "one-point" method using Chem Draw 3D software package, which enables taking into account chemical, physical, and physicochemical features of substrates, reagents and "metal-reagent" systems during simulation (Figure 7).

Having analyzed the probability of formation of "metal-reagent" complexes by the criterion of energy of complexation (Ecom, $\mathrm{Kcal} / \mathrm{mol}$ ), it was concluded that tributyl phosphate shows the required activity for the extraction of $\mathrm{Fe}, \mathrm{Ni}, \mathrm{V}$, Ti, etc.

The newly obtained suspension (with tributyl phosphate) was processed for $15 \mathrm{~min}$ with ultrasound at frequency within $44 \mathrm{KHz}$. After that, the oil residue, which contains asphaltene, was fed into a chamber with a stirrer, where cavitation treatment was performed. At this stage, cavitation breaks a continuous chain, with destruction of the bond between individual parts of the molecules that change the structural viscosity, that is, temporary breakdown of the Van der Waals bonds. C-C bonds in paraffin molecules are destroyed under the influence of high-intensity long cavitation, what results in changes in physical chemical composition (reduced molecular weight, crystallization temperature, etc.) and properties of petroleum products (viscosity, density, flash point, etc.). In hydrocarbon, raw material cavitation molecules are destroyed due to microcracking and ionization processes. Thus, the asphaltene fraction obtained after cavitation treatment contains most of such 
metals as nickel, iron, titanium, etc. (Figure 8), and the light fraction contains $\mathrm{V}$ and $\mathrm{Mn}$ metalloporphins, which can be a raw material for the pharmaceutical industry.

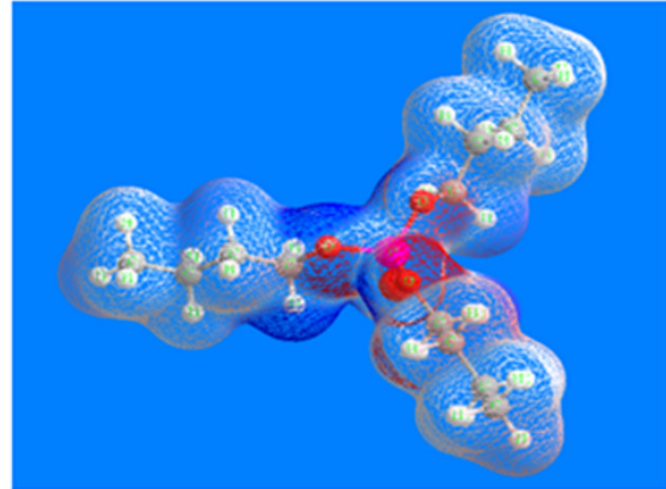

(a) Stretch: 1.2944

Bend: 5.6172

Stretch-Bend: 0.0154

Torsion: 26.0486

Non-1,4VDW: -4.8074

1,4 VDW: 14.0207

Dipole/Dipole: -8.7488

Total Energy: $33.4400 \mathrm{kcal} / \mathrm{mol}$

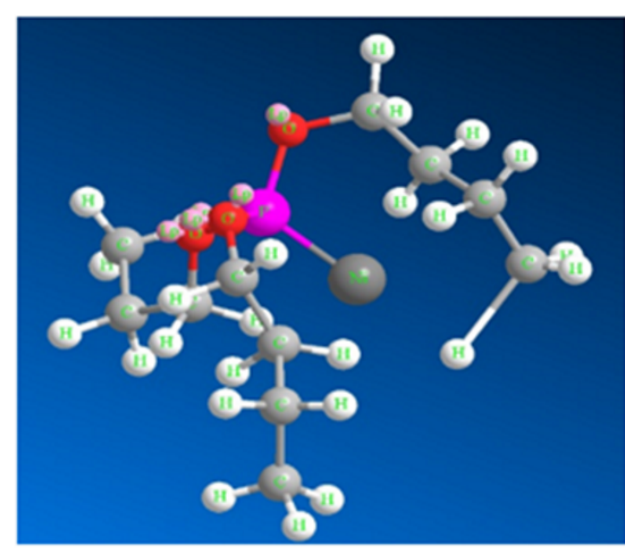

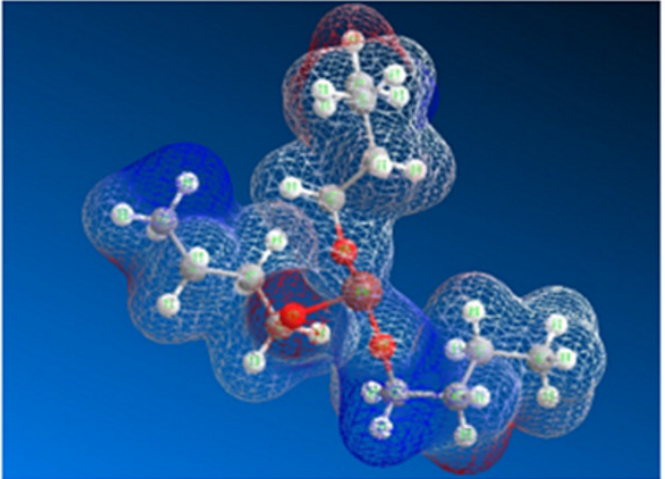

(b) Stretch: 0.7464

Bend: 3.2491

Stretch-Bend: 0.3227

Torsion: 0.8508

Non-1,4VDW: -6.5294

1,4 VDW: 10.7189

Dipole/Dipole: 1.3665

Total Energy: $10.7240 \mathrm{kcal} / \mathrm{mol}$

(c) Stretch: 1.0316

Bend: 7.7830

Stretch-Bend: 0.4847

Torsion: 5.2914

Non-1,4VDW: -29.4345

1,4 VDW: 12.3968

Dipole/Dipole: -4.3391

Total Energy: -6.7860 kcal/mol

Figure 7. Modeling of possible metal extraction products with tributyl phosphate: (a)-Tributyl phosphate molecule, (b) - molecule of the proposed product of iron extraction with tributyl phosphate, (c) - molecule of the proposed product of nickel extraction with tributyl phosphate.
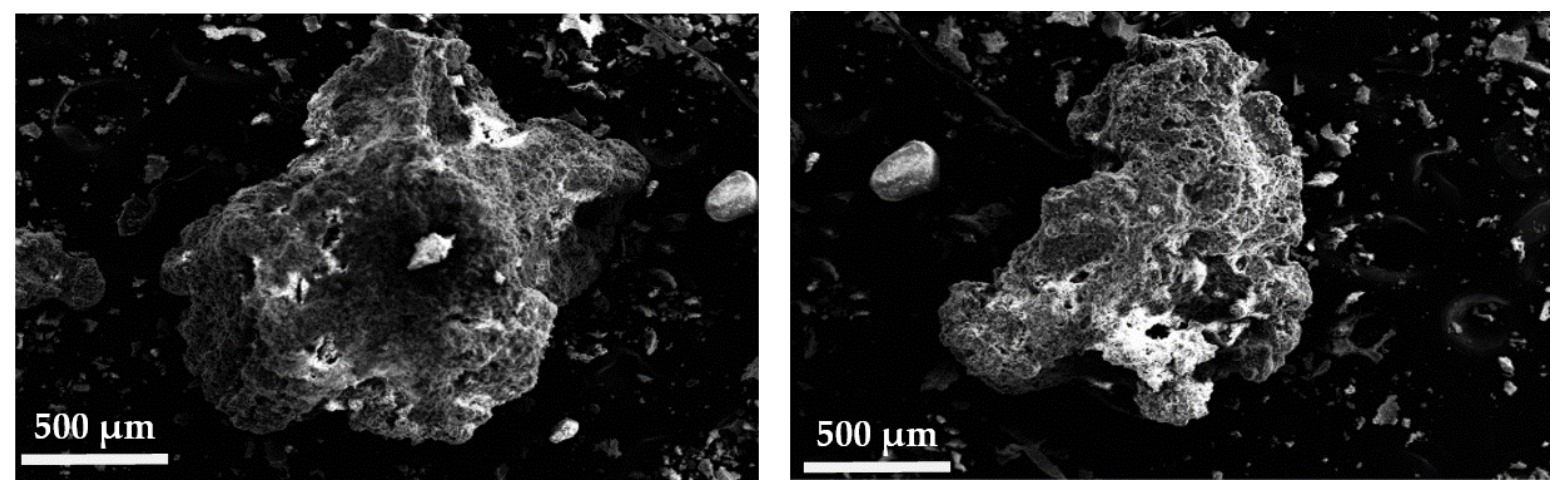

Figure 8. Microphotographs of the asphalt fraction associated with metals. 
To reextract metals from the asphaltene fraction, a number of experiments were performed with the use of magnetite crushed to a particle size of $-0.071 \mathrm{~mm}$. Magnetite is characterized by high sorption capacity. In this case, magnetic agglomerates after sorption may be quickly and effectively removed from the suspension by applying a magnetic field. However, it should be noted that the efficiency of magnetic iron oxides for the sorption process depends on the size and surface characteristics of the particles [19-25]. Magnetite was added to the suspension in an amount of $1 \mathrm{~g}$. Contact time of magnetite with the suspension was $8 \mathrm{~h}$ at room temperature. The obtained magnetic agglomerates were analyzed in terms of metal content using a spectral method with inductively coupled plasma on iCAP6300DUO spectrometer (Figure 9 and Table 3).

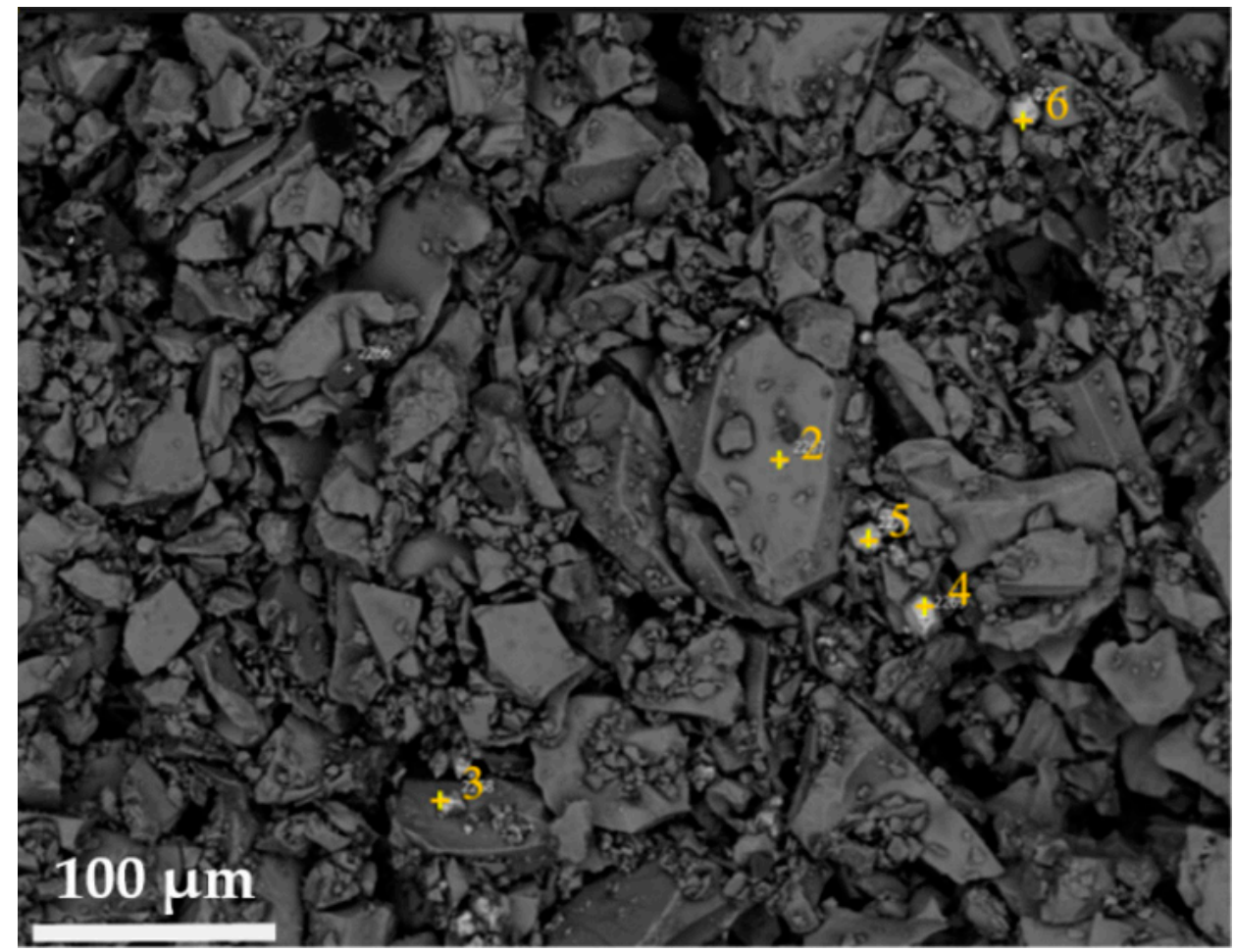

Figure 9. The micrograph of magnetic agglomerate.

Table 3. The results of microprobe analysis.

\begin{tabular}{ccccccccccc}
\hline $\begin{array}{c}\text { No. of } \\
\text { Spectrum }\end{array}$ & $\mathbf{A l}$ & $\mathbf{S i}$ & $\mathbf{S}$ & $\mathbf{T i}$ & $\mathbf{V}$ & $\mathbf{F e}$ & $\mathbf{N i}$ & $\mathbf{P r}$ & $\mathbf{N d}$ & $\mathbf{G d}$ \\
\hline 1 & 0.7 & 1.47 & 0.58 & 18.22 & 10.13 & 68.74 & 0.16 & - & - & - \\
2 & 0.35 & 1.43 & 0.42 & 24.26 & 1.02 & 69.45 & 3.07 & - & - & - \\
3 & 0.61 & 0.51 & 0.23 & 5.91 & 4.31 & 61.7 & 0.52 & 5.23 & 17.47 & 3.51 \\
4 & 1.08 & - & - & 1.53 & 2.28 & 66.2 & 2.01 & 5.26 & 17.54 & 4.1 \\
5 & 0.9 & 0.21 & - & 2.63 & 0.33 & 64.04 & 4.67 & 5.08 & 17.85 & 4.29 \\
6 & 0.9 & 0.65 & - & 5.4 & 0.33 & 62.1 & 3.01 & 5.5 & 17.28 & 4.83 \\
\hline
\end{tabular}

As it can be seen from Table 3, metals such as titanium, iron, and some rare-earth metals are well sorbed to the ground magnetite. It is possible to use other mineral systems (for example, activated schungite) as sorbents, which will enable extracting nickel, vanadium, zinc, and molybdenum more effectively.

As a result, several products are produced using this technology: metal porphyrins, magnetic fraction (Table 4) and clarified fraction in the refinery. 
Table 4. Results on extraction of metals from magnetic fraction.

\begin{tabular}{cc}
\hline Metal & Recovery (\%) \\
\hline $\mathrm{Ti}$ & 45.2 \\
$\mathrm{Fe}$ & $87.3^{*}$ \\
$\mathrm{Ni}$ & 31.9 \\
$\mathrm{~V}$ & 41.8 \\
\hline
\end{tabular}

*-having regard to sorbent.

In addition to extracting heavy metals, this technology allows us to reduce the density of heavy petroleum feedstocks by 5-10 API degrees while reducing the viscosity by $80-90 \%$ and sulfur content by $40 \%$.

\section{Conclusions}

Based on theoretical and experimental studies, a diagram of extracting metals from heavy oils was developed and implemented, realizing the principle of "demetallization of heavy oils-a complex problem", aiming to increase the yield of light fractions and "transport" ability of oil, and extracting metals from heavy asphaltene-resinous fraction. The main feature of this technology is the consistent use of acoustic and cavitation effects on oil-water suspensions with additives of polar solvents, which enables improving the mass transfer efficiency at SDA stage, thereby reducing the required extraction time. Kerosene and tributyl phosphate were used as extractants at different stages of processing crude oil from the mixotropic series. Studying the specific features of the mechanisms of interaction of extractants with recoverable metals on the grounds of a combination of values of quantum chemical, physical chemical, and structural parameters of metals and extractable "metal-extractant" systems enabled substantiating the use of kerosene and tributyl phosphate at various processing stages for extraction of heavy metals (metal ions) from heavy oils. The degree of recovery of hetero compounds associated with metals using kerosene and tributyl phosphate reaches $37.98 \%$ and $40.72 \%$, respectively. Extraction of $45.2 \%$ of titanium, $87.3 \%$ of iron, $31.9 \%$ of nickel, and $41.8 \%$ of vanadium into the magnetic product was achieved.

Thus, the integration of the processes of co-production of concentrates containing strategic metals: heavy (Fe, Ni), rare (Ti, V), rare earths ( $\mathrm{Pr}, \mathrm{Nd}, \mathrm{Gd})$, etc.), into the production flows of large-scale oil refining may lead to the fact that the profitability of their extraction from hydrocarbon raw materials will be significantly higher than that for technologies for obtaining metals from traditional, although difficult-to-enrich, ore raw materials.

Author Contributions: T.A., conceived, designed the experiments, and analyzed the data; D.H., implementation and processing of the analysis results; N.N. and A.R., performed the experiments. All authors have read and agreed to the published version of the manuscript.

Funding: This research received no external funding.

Institutional Review Board Statement: Not applicable.

Informed Consent Statement: Not applicable.

Data Availability Statement: The data presented in this study are available in the article.

Conflicts of Interest: The authors declare no conflict of interest.

\section{References}

1. Litvinenko, V.S. Digital economy as a factor in the technological development of the mineral sector. Nat. Resour. Res. 2020, 29, 1521-1541. [CrossRef]

2. Makhovikov, A.B.; Katuntsov, E.V.; Kosarev, O.V.; Tsvetkov, P.S. Digital transformation in oil and gas extraction. In InnovationBased Development of the Mineral Resources Sector: Challenges and Prospects, Proceedings of the 11th Conference of the Russian-German Raw Materials, Potsdam, Germany, 7-8 November 2018; CRC Press: Boca Raton, FL, USA, 2019; pp. 531-538.

3. Litvinenko, V. The Role of Hydrocarbons in the Global Energy Agenda: The Focus on Liquefied Natural Gas. Resources 2020, 9 , 59. [CrossRef] 
4. Molchanov, K.; Romasheva, N. Conceptual approach for building a balanced portfolio of projects in oil and gas companies in exploration and production sector. In E3S Web of Conferences; EDP Sciences: Ulis, France, 2019; Volume 140, p. 03004.

5. Andrukhova, O.V.; Razmanova, C.V. Oilfield service companies within the digitalization of the economy: Assessment of the prospects for innovative development. J. Min. Inst. 2020, 244, 482-492.

6. Sukhanov, A.A.; Yakutseni, V.P.; Petrov, Y.E. Petroleum geology. Theory Pract. 2012, 7, 23.

7. Akhmetov, S.A. The technology of deep processing of oil and gas: A manual for schools; Guillem: Ufa, Russia, $2002 ;$ p. 672.

8. Muslimov, R.X.; Romanov, G.V.; Kayukova, G.P. Integrated development of heavy oil and natural bitumen Perm Tatarstan system. Kazan: Publishing house "Fan"; The Academy of Sciences: Kazan, Russia, 2012; p. 396.

9. Hadjiyev, S.N.; Shpirt, M.Y. Microelements in the Oils and Products of Their Processing. Nauka: Ekaterinburg, Russia, 2012; p. 222.

10. Samedova, F.I.; Rashidova, S.Y.; Kasumova, A.M.; Kuliev, N.A. Supercritical Fluids. Theory Pract. 2013, 8, 53.

11. Shpirt, M.Y.; Sadowski, V.V. Microelements of Combustible Minerals; Kuchkovo Field: Moscow, Russia, 2010; Book 4, p. 384.

12. Litvinenko, V.S.; Kozlov, A.V.; Stepanov, V.A. Hydrocarbon potential of the Ural-African transcontinental oil and gas belt. J. Pet. Explor. Prod. Technol. 2017, 7. [CrossRef]

13. Kuzhaeva, A.A.; Dzhevaga, N.V.; Berlinskii, I.V. The processes of hydrocarbon conversion using catalytic systems. J. Phys. Conf. Ser. 2019, 1399, 022057. [CrossRef]

14. Kuzhaeva, A.; Dzhevaga, N.; Berlinskii, I. Modernization of catalyst systems for the processes of hydrocarbon conversion to synthesis gas. ARPN J. Eng. Appl. Sci. 2019, 14, 3535-3543.

15. Díaz-Boffelli, G.; Ancheyta, J.; Muñoz, J.A.D.; Centeno, G. Experimental study and economic analysis of heavy oil partial upgrading by solvent deasphalting-hydrotreating. Energy Fuels 2018, 32, 55-59. [CrossRef]

16. Aleksandrova, T.N.; Romashev, A.O.; Aleksandrov, A.V. About modeling of rheological properties of heavy oil suspensions. Oil Ind. 2016, 5, 68-70.

17. Tribovillard, N.; Riboulleau, A.; Lyons, T.; Baudin, F. Enhanced trapping of molybdenum by sulfurized marine organic matter of marine origin in Mesozoic limestones and shales. Chem. Geol. 2014, 213, 385-401. [CrossRef]

18. Mossman, D.; Gauthier-Lafaye, R.; Jackson, S. Black shales, organic matter, ore genesis and hydrocarbon generation in the Paleoproterozoic Franceville Series, Gabon. Precambrian Res. 2005, 137, 253-272. [CrossRef]

19. Zhang, J.; Ren, D.; Zhu, Y.; Chou, C.-L.; Zeng, R.; Zheng, B. Mineral matter and potentially hazardous trace elements in coals from Qianxi Fault Depression Area in south-western Guizhou, China. Int. J. Coal Geol. 2004, 57, 49-61. [CrossRef]

20. Kler, V.R.; Nenakhova, F.Y.; Shpirt, M.Y.; Saprykin, F.Y. Metallogeny and Geochemistry of Carboniferous and Shale Strata of the Soviet Union. Regularities of Element Concentrations and Methods of Their Study; Nauka: Ekaterinburg, Russia, 1988; p. 256.

21. Yudovich, Y.E.; Ketris, M.P. Elements_Impurities in Black Shales; Nauka: Ekaterinburg, Russia, 1994; p. 304.

22. Nikitin, M.N.; Gladkov, P.D.; Kolonskikh, A.V.; Petukhov, A.V.; Mikheev, A.I. Analysis of rheological properties of yaregskoe field heavy high-viscosity oil. J. Min. Inst. 1. 2016, 195, 73-77.

23. Dolgii, I.E. Methods to enhance oil recovery in the process of complex field development of the Yarega oil and titanium deposit. $J$. Min. Inst. 2017, 231, 263-297.

24. Santos, H.M. The Power of Ultrasound. In Ultrasound in Chemistry: Analytical Applications; Santos, H.M., Lodeiro, C., CapeloManinez, J.-L., Eds.; John Wiley \& Sons: Hoboken, NJ, USA, 2009; pp. 1-16.

25. Yudovich, Y.E.; Ketris, M.P. The Inorganic Substance of Coals; Nauka: Ekaterinburg, Russia, 2002; p. 422. 